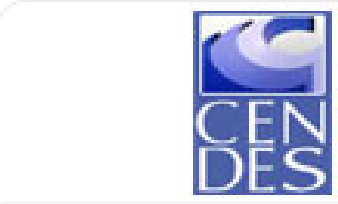

$\sqrt{1+20}$

\section{Cuadernos del CENDES}

ISSN: 1012-2508

cupublicaciones@ucv.ve

Universidad Central de Venezuela

Venezuela

Mayorga, René Antonio

La crisis del sistema de partidos políticos en Bolivia: causas y consecuencias

Cuadernos del CENDES, vol. 21, núm. 57, septiembre-diciembre, 2004, pp. 83-114

Universidad Central de Venezuela

Caracas, Venezuela

Disponible en: http://www.redalyc.org/articulo.oa?id=40305704

Cómo citar el artículo

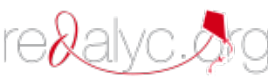

- Número completo

- Más información del artículo

Página de la revista en redalyc.org

Sistema de Información Científica

Red de Revistas Científicas de América Latina, el Caribe, España y Portugal

Proyecto académico sin fines de lucro, desarrollado bajo la iniciativa de acceso abierto 


\title{
La crisis del sistema de partidos políticos en Bolivia: causas y consecuencias
}

\author{
RENÉ ANTONIO MAYORGA
}

\section{Resumen}

El artículo analiza la metamorfosis y las tendencias de descomposición del sistema de partidos provocadas por las elecciones generales de junio de 2002. Argumenta que causas estructurales como el agotamiento de los gobiernos de coalición subyacen en este proceso. Concluye explorando algunas de las consecuencias más serias de la crisis del sistema de partidos: la ruptura de los consensos políticos, la crisis de hegemonía y la creciente ingobernabilidad del país determinada por un gobierno débil sin apoyo de los partidos políticos.

\section{Palabras clave}

Crisis del sistema de partidos / Multipartidismo polarizado / Erosión del Estado / Ingobernabilidad / Gobierno sin partidos

\section{Abstract}

This article examines the changes and decomposition of the Bolivian party system which were triggered by the general elections of June 2002. It argues that structural causes like the exhaustion of coalition governments underlie these changes. The article concludes that the crisis of the party system provoked serious consequences: the rupture of consensus-building, the crisis of hegemony, and the increasing ingovernability of the country stemming from a government without party support.

\section{Key words}

Crisis of party system / Polarized multipartism / State erosion / Ungovernability / Partyless government 
Desde hace muchos años, el sistema democrático en la región andina está asediado por una compleja crisis de gobernabilidad que se origina principalmente en la fragmentación de la representación política y de los sistemas de partidos, así como en el desmantelamiento de las capacidades de los Estados para hacer frente a las crecientes demandas y conflictos sociales. En este panorama, Bolivia era una relativa excepción debido a una estabilidad política y económica que se basó en tres factores: un moderado crecimiento económico del 4 por ciento anual entre 1989 y 1997, gobiernos de coalición estables, y reformas institucionales del Estado que evitaron alternativas neopopulistas y autoritarias similares a las de Alberto Fujimori y Hugo Chávez. Sin embargo, a partir del gobierno de Hugo Bánzer, el estancamiento de la economía, la crisis fiscal, la polarización política, el surgimiento de movimientos indígenas contestatarios y la multiplicación anómica de demandas y conflictos sociales y regionales se constituyeron en manifestaciones de una prolongada crisis de gobernabilidad que ha ensombrecido las perspectivas de supervivencia del régimen democrático.

La caída del gobierno de Gonzalo Sánchez de Lozada en octubre de 2003 -a raíz de una revuelta popular limitada al occidente del país- fue el clímax de esta crisis. No sólo significó la derrota política de un líder político y del principal partido de gobierno, sino tuvo también dos consecuencias catastróficas para el sistema político: el derrocamiento de dos partidos relevantes -el Movimiento Nacionalista Revolucionario (MNR) y el Movimiento de Izquierda Revolucionaria (MIR) - que conformaron los gobiernos democráticos desde 1985, y el fin (¿temporal?) del sistema de gobiernos de coalición. Como resultado de esta crisis de gobierno y Estado, el gobierno de Carlos Mesa lanzó un frágil experimento de «gobierno sin partidos» que ha estado atrapado en una lógica de ingobernabilidad. En consecuencia, Bolivia plantea, en la actualidad, la misma problemática de sistemas políticos en los cuales dos requisitos fundamentales de la viabilidad de regímenes democráticos se están desvaneciendo: la existencia de partidos políticos y de Estados capaces de cumplir con sus funciones básicas. La democracia boliviana se encuentra particularmente en una grave encrucijada porque los partidos políticos como actores claves del sistema político -sin ellos no hay democracia- están desgastados y arrinconados en un panorama antipolítico y antipartido que ellos mismos han creado.

Dado que los partidos no han estado a la altura de los desafíos económicos y sociales, es necesario cambiar de óptica en el análisis de la crisis que los afecta. El enfoque teórico que planteo en este trabajo parte de la hipótesis principal de que los partidos políticos y el sistema que ellos conformaron no se enfrentan a una serie crisis de descomposición sobre todo por la volatilidad de la representación política -éste es el planteamiento predominante que remite el problema a una crisis de confianza y credibilidad, lo cual es casi una tautología-, sino por las deficiencias y fracasos de los partidos en la 
gestión gubernamental y estatal. La crisis de la representación política es una consecuencia de la crisis de los partidos como actores gubernamentales y no a la inversa. Desde esta perspectiva, la cuestión esencial sería: ¿por qué los partidos no han tenido la capacidad de cumplir suficientemente con las funciones que la teoría política y el sistema democrático les atribuyen? Y como derivación, también el problema que suscita la crisis en Bolivia y en la región andina: ¿ pueden los movimientos sociales, o podrán las llamadas «agrupaciones ciudadanas» y los candidatos independientes, mejorar la representación política y sustituir a los partidos políticos, como postulan la nueva Constitución Política del Estado y muchos dirigentes sociales, incluso dirigentes políticos como el ex-presidente Jorge Quiroga? ¿Es posible la democracia sin partidos políticos? Son tan grandes los contrastes entre la teoría de los partidos y el déficit de funcionamiento de éstos en América Latina que sorprende que haya un vacío enorme en la reflexión sobre las causas de esta gran brecha. ${ }^{1}$

Este artículo se propone abordar algunas causas que, a mi criterio, han provocado la crisis actual de los partidos políticos. En primer lugar, analiza tanto los cambios del sistema de partidos políticos ocurridos en las elecciones de 2002 como sus implicaciones principales. En segundo lugar, trata de detectar las tendencias de descomposición del sistema de partidos y del liderazgo político en el nuevo escenario que emergió con el derrumbe de Sánchez de Lozada. Finalmente, analiza el gobierno apartidista de Mesa como resultado de esta crisis e intenta explorar las perspectivas más probables que se derivan de este escenario para los partidos políticos.

\section{Recomposición efímera del sistema de partidos: del multipartidismo moderado al multipartidismo polarizado}

A partir de las elecciones de 1985, Bolivia tuvo un sistema multipartidista moderado que descansaba en un eje central o trípode de tres partidos -MNR, MIR y Acción Democrática Nacionalista (ADN)-, cada uno de los cuales fue el pivote de cuatro gobiernos de coalición. En términos históricos, la constitución de este sistema de partidos fue crucial. Antes de la revolución de 1952, Bolivia había conocido -en el contexto de un sistema político oligárquico- un régimen multipartidista excluyente y de reducida capacidad de representación. La revolución de 1952 trajo como consecuencia no un sistema de partidos, sino el predominio absoluto de un partido verdaderamente hegemónico -el MNR- que llegó a confundirse con el Estado, asemejándose al Partido Revolucionario Institucional (PRI) mexicano, pero sin llegar obviamente a alcanzar la solidez y longevidad extrema de éste. Sólo con la transición a la democracia se fue configurando un sistema multipartidista que devino en pocos años de fragmentado y polarizado en un sistema moderado -sustentado en el 
consenso básico sobre la necesidad de impulsar la democracia representativa y la economía de mercado- y en el cual ningún partido ejerció un real dominio hegemónico.

Después de confrontaciones destructivas entre los partidos, y entre éstos y los movimientos sociales durante la fase de transición a la democracia, las organizaciones políticas llegaron a conformar un sistema de partidos, es decir, un sistema de interacción partidaria de acuerdo con reglas de juego que norman la competencia democrática por el poder. A partir de 1985, y coincidiendo con las reformas estructurales de la economía, el sistema de partidos empezó a perfilarse como un sistema multipartidista moderado, caracterizado por tres elementos claves: una distancia ideológica relativamente leve entre los partidos grandes, una tendencia a la formación de coaliciones entre partidos de distintas posiciones, y una competencia partidaria predominantemente centrípeta (Sartori, 1987:227).

Cuatro factores históricos importantes incidieron en la formación de este sistema de partidos: 1) la derrota y el desplazamiento político de los partidos de la izquierda tradicional y del movimiento sindical, orientados desde la década de los cincuenta a objetivos radicales de cambio social y político; 2) la emergencia de posiciones centristas y gradualistas en amplios sectores de la sociedad; 3) la política económica de ajuste estructural tras la crisis de la economía estatista; y 4) la concertación y los acuerdos interpartidarios que hicieron posible gobiernos de coalición. Este fue un cambio institucional decisivo para el desarrollo del sistema de partidos porque los patrones de interacción y competencia se orientaron hacia la negociación y concertación entre los partidos y hacia una convergencia programática en cuestiones de política económica y reforma política: por lo tanto, hacia una competencia de tipo pragmático de propuestas concretas más que a una confrontación estéril de modelos utópicos de organización social y política. En consecuencia, el gran viraje político a mediados de los ochenta se produjo gracias a la implantación de una lógica democrática de acuerdos y consensos entre partidos que reemplazó la lógica tradicional de guerra implacable entre los adversarios políticos, desbrozando así el terreno para una «democracia pactada» (Mayorga, 1991).

¿Cuáles fueron los rasgos esenciales del sistema multipartidista? En primer lugar, tuvo lugar una reducción progresiva y sustancial del número de partidos y, por consiguiente, una disminución cualitativa del grado de fragmentación partidaria. La reducción del número de partidos llevó a un formato de sistema multipartidista moderado en torno a cinco partidos con representación parlamentaria importante. Con altibajos, el sistema empezó a experimentar -a partir de las elecciones de 1985- una fuerte disminución de sus componentes como se comprueba en la diferencia entre partidos y/o frentes electorales y partidos y/o frentes parlamentarios, es decir, aquellos que lograron acceder al Parlamento (cuadro 1). 
La crisis del sistema de partidos políticos

en Bolivia: causas y consecuencias

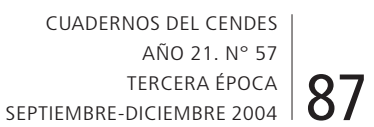

Cuadro 1

Partidos electorales y partidos parlamentarios

\begin{tabular}{ccc}
\hline $\begin{array}{c}\text { Partidos } \\
\text { electorales }\end{array}$ & $\begin{array}{c}\text { Año de } \\
\text { elección }\end{array}$ & $\begin{array}{c}\text { Partidos } \\
\text { parlamentarios }\end{array}$ \\
\hline 8 & 1979 & 7 \\
13 & 1980 & 11 \\
18 & 1985 & 10 \\
10 & 1989 & 5 \\
14 & 1993 & 8 \\
10 & 1997 & 7 \\
\hline
\end{tabular}

Fuente: Elaboración propia basada en datos de la CNE.

El aspecto esencial de este proceso no sólo fue el descenso del número de partidos, sino la emergencia de una estructura de tríada partidista (MNR, MIR, ADN), es decir, de tres partidos relevantes en los cuales estuvieron concentrados el potencial de gobierno y la capacidad de coalición. En las elecciones de 1985 a 1997, estos tres partidos lograron conquistar conjuntamente el 65 por ciento y el 57 por ciento de los votos y el 86 por ciento y el 54 por ciento de los escaños, formando con la ayuda de partidos menores dos bloques (ADN/MIR y MNR) que se alternaban en el gobierno en coaliciones de diversa índole (cuadro 2). Nuevas agrupaciones políticas como Conciencia de Patria (Condepa), Unión Cívica Solidaridad (UCS) y otros partidos menores sólo complementaron el «eje político» de tres partidos decisivos para la formación de gobiernos. En efecto, los resultados de las elecciones de 1993 y 1997 ampliaron el espectro de partidos con importancia parlamentaria de tres a cinco partidos, con la inclusión de Condepa y UCS.

En segundo lugar, un rasgo definitorio del sistema multipartidista moderado fue la persistencia de mayorías relativas, razón por la cual ningún partido tuvo una verdadera hegemonía política. Pero la ausencia de una hegemonía mono o bipartidista fue compensada por la formación de un trípode de partidos capaz de incorporar a nuevas fuerzas políticas. En tercer lugar, en el contexto de la nueva política económica, el sistema partidario desarrolló un tipo de competencia centrípeta que redujo sustancialmente la tradicional polarización y los antagonismos entre las tendencias de democratización liberal y la izquierda tradicional. Las distintas experiencias partidarias en los gobiernos de coalición -y sobre todo, la ruptura del Pacto por la Democracia entre el MNR y ADN en 1989- trajo consigo además un patrón de competencia bipolar, puesto que la alternancia en el poder se ha producido entre el MNR, por una parte, y ADN en alianza con el MIR, por otra.

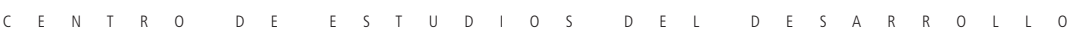


Cuadro 2

Votos y escaños por partido, 1985-1997

Cámara de Diputados

\begin{tabular}{|c|c|c|c|c|c|c|c|c|c|c|c|c|}
\hline \multirow{2}{*}{ Partido } & \multicolumn{3}{|c|}{ Julio, 1985} & \multicolumn{3}{|c|}{ Mayo, 1989} & \multicolumn{3}{|c|}{ Junio, 1993} & \multicolumn{3}{|c|}{ Junio, 1997} \\
\hline & $\begin{array}{c}\% \\
\text { votos }\end{array}$ & $\begin{array}{c}\mathrm{N}^{\circ} \\
\text { escaño }\end{array}$ & $\begin{array}{c}\% \\
\text { escaños }\end{array}$ & $\begin{array}{c}\% \\
\text { votos }\end{array}$ & $\begin{array}{c}\mathbf{N}^{\circ} \\
\text { escaños }\end{array}$ & $\begin{array}{c}\% \\
\text { escaños }\end{array}$ & $\begin{array}{c}\% \\
\text { votos }\end{array}$ & $\begin{array}{c}\mathbf{N}^{\circ} \\
\text { escaños }\end{array}$ & $\begin{array}{c}\% \\
\text { s escaños }\end{array}$ & $\begin{array}{c}\% \\
\text { votos }\end{array}$ & $\begin{array}{c}\mathbf{N}^{\circ} \\
\text { escaños }\end{array}$ & $\begin{array}{c}\% \\
\text { escaños }\end{array}$ \\
\hline ADN & 28,60 & 41 & 31,54 & 22,07 & 38 & 29,23 & - & - & - & 22,26 & 32 & 24,62 \\
\hline MNR & 24,60 & 43 & 33,08 & 23,07 & 40 & 30,77 & 36,22 & 52 & 40,00 & 18,20 & 26 & 20,00 \\
\hline MIR & 8,80 & 15 & 11,54 & 19,64 & 33 & 25,38 & - & - & - & 16,80 & 24 & 18,46 \\
\hline AP & - & - & - & - & - & - & 21,45 & 35 & 26,92 & & & \\
\hline UCS & - & - & - & - & - & - & 14,02 & 20 & 16,15 & 16,11 & 21 & 16,15 \\
\hline Condepa & - & - & - & 11,02 & 10 & 7,69 & 14,56 & 13 & 10,00 & 17,16 & 19 & 14,62 \\
\hline MBL & - & - & - & - & - & - & 5,46 & 7 & 5,38 & 3,09 & 4 & 3,08 \\
\hline IU & - & - & - & 7,21 & 9 & 6,92 & - & - & - & 3,71 & 4 & 3,08 \\
\hline MNRI & 4,80 & 8 & 6,15 & - & - & - & - & - & - & - & - & - \\
\hline MNRV & 4,20 & 6 & 4,62 & - & - & - & - & - & - & - & - & - \\
\hline PSI & 2,20 & 5 & 3,85 & - & - & - & - & - & - & - & - & - \\
\hline FPU & 2,20 & 4 & 3,08 & - & - & - & - & - & - & - & - & - \\
\hline PDC & 1,30 & 3 & 2,31 & - & - & - & - & - & - & - & - & - \\
\hline EJE & - & - & - & - & - & - & 1,30 & 1 & 0,77 & - & - & - \\
\hline FSB & 1,10 & 3 & 2,31 & - & - & - & - & - & - & - & - & - \\
\hline Mrtkl & 1,80 & 2 & 1,54 & - & - & - & - & & & - & - & - \\
\hline Arbol & - & - & - & - & - & - & 1,30 & 1 & 0,80 & - & - & - \\
\hline ASD & - & - & - & - & - & - & 1,30 & 1 & 0,80 & - & - & - \\
\hline \multicolumn{2}{|c|}{ Formula electoral } & \multicolumn{2}{|c|}{$\begin{array}{l}\text { Doble cociente } \\
\text { y restos mayores }\end{array}$} & \multicolumn{3}{|c|}{$\begin{array}{l}\text { Doble cociente } \\
\text { y restos mayores }\end{array}$} & \multicolumn{3}{|c|}{ Sainte-Laguë } & \multicolumn{2}{|c|}{ D'Hondt } & \\
\hline \multicolumn{2}{|c|}{ Barrera legal } & \multicolumn{2}{|c|}{ Ninguna } & \multicolumn{3}{|c|}{ Ninguna } & \multicolumn{3}{|c|}{ Ninguna } & \multicolumn{2}{|c|}{$3 \%$} & \\
\hline \multicolumn{2}{|c|}{ Desproporcio-nalidad } & \multicolumn{2}{|c|}{3,17} & \multicolumn{3}{|c|}{6,88} & \multicolumn{3}{|c|}{6,44} & \multicolumn{2}{|c|}{4,41} & \\
\hline
\end{tabular}

Fuente: Elaboración propia con base en datos de la CNE.

Es cierto que entre 1985 y 2000 nuevas fracturas ideológico-políticas entre los partidos que abogaban por la democracia representativa, la economía de mercado y el rol regulador del Estado, y aquellos que expresaban orientaciones populistas, comunitaristas y particularismos étnico-culturales, marcaron la lucha política. Sin embargo, no tuvieron una influencia decisiva en el sistema político. Al contrario, la dinámica de relativa polarización 
que se desató con la emergencia de Condepa y UCS -dos partidos populistas de distinto signo, impulsados inicialmente por tendencias antisistémicas- fue neutralizada por los efectos centrípetas del sistema de partidos y del sistema de gobierno, llevando a una rápida integración de estos partidos neopopulistas y a la virtual desaparición de las organizaciones de la izquierda marxista (Mayorga, 1995). Las contradicciones tradicionales entre la izquierda marxista-populista y las corrientes de derecha antidemocráticas se desvanecieron ampliamente. Como resultado, el espectro político quedó claramente definido por los partidos del "centro democrático» y un ambiguo proceso de resurgimiento y simultáneamente de rápida absorción de actores y movimientos neopopulistas. En este panorama, hasta las elecciones de 2002 no cuajaron los esfuerzos de organizar partidos o movimientos políticos sobre principios exclusivamente étnico-culturales y concepciones fundamentalistas. Por un lado, la política de inclusión en el sistema de representación continuaba siendo una de las asignaturas pendientes de mayor relevancia de los partidos políticos porque éstos no tuvieron la capacidad de representar las demandas étnicoculturales; por otro lado, se hacía evidente, en la década de los ochenta, la poca fuerza de las tendencias fundamentalistas y puramente indigenistas.

En resumen, cinco fueron los rasgos estructurales fundamentales del sistema multipartidista boliviano: un número efectivo de cinco partidos; la vigencia de un formato tripartidista, es decir, de una tríada de partidos relevantes para la formación de coaliciones gubernamentales con mayoría parlamentaria; el pluralismo moderado y una polarización ideológica leve entre los partidos relevantes del sistema; la persistencia de mayorías relativas; y una competencia partidaria predominantemente centrípeta. ${ }^{2}$

\section{Las consecuencias de las elecciones generales de junio de $\mathbf{2 0 0 2}$}

Para comprender la actual situación política de un gobierno sin base partidaria y los problemas principales del sistema de partidos, es indispensable remontarse a las elecciones presidenciales y parlamentarias del 30 de junio de 2002, debido a los profundos efectos que tuvieron sobre el sistema de partidos. A mi criterio, estos efectos fueron fundamentalmente: a) una significativa reconfiguración de los partidos relevantes del sistema; b) una fuerte polarización entre los partidos predominantes y nuevas fuerzas políticas; c) un avance cualitativo de la representación política por la inclusión de sectores indígenas y campesinos al sistema político; y d) una importante redistribución territorial del voto.

2 La aplicación del art. 90 de la Constitución -que determina la elección congresal del presidente cuando ningún candidato ha obtenido la mayoría absoluta de votos- ha sido en este proceso el factor decisivo y no tanto el sistema de representación proporcional que más bien ha estimulado la aparición de pequeños partidos y la dispersión de la representación (Mayorga, 2001b). Al arraigarse la lógica de los pactos políticos, esta disposición constitucional dio cobertura a una dinámica del sistema de partidos cada vez más orientada hacia el centro, menos fragmentada y polarizada.

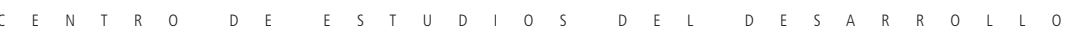


En primer lugar, las elecciones de junio de 2002 generaron una recomposición significativa del sistema de partidos políticos. La mayoría de los analistas había pronosticado entonces un derrumbe inminente del sistema. Pero esto no sucedió, porque a pesar de la dualidad de actitudes del MAS, el MIP y el NFR frente al orden democrático, las reglas de juego de la competencia política no perdieron su vigencia. El sistema de partidos se mantuvo como un conjunto estable de partidos que interactúan según reglas de juego aceptadas por todos. Lo que ocurrió fue un serio desgaste del sistema de partidos por la desaparición y declinación de algunos de sus componentes y la aparición de otros. Esto equivalía, en rigor, a una metamorfosis, pero no a una disolución del sistema de partidos como tal. ${ }^{3}$ Es indudable que el trípode de partidos se deshizo. Habiendo obtenido en las elecciones de 1997 el 22,26 por ciento de los votos y 45 escaños, ADN sufrió una catastrófica derrota, convirtiéndose en un partido marginal y al borde de la desaparición puesto que logró sólo el 3,4 por ciento de votos y 5 escaños. Esta catastrófica derrota fue previsible y casi un resultado esperado debido a la pésima gestión del gobierno de Bánzer, cuya muerte terminó de comprometer seriamente el futuro del partido. Para el sistema de partidos, la marginalización de ADN supuso ciertamente el comienzo del ocaso del eje de partidos que sostuvo el proceso democrático hasta ahora.

Sin embargo, la descomposición del trípode MNR, MIR, ADN no trajo como consecuencia inmediata el derrumbe conjunto de los tres partidos que lo conformaban ni tampoco el colapso total del sistema de partidos. El trípode dejó de existir, pero el MNR y el MIR mantuvieron provisionalmente, aunque debilitados, su posición de partidos relevantes con capacidad de coalición para formar una nuevo gobierno. El MNR ganó las elecciones por una ligera mayoría relativa del 22,46 por ciento de los votos; sin embargo, obtuvo la bancada más fuerte (47 escaños) mientras que el MIR, con el 16,32 por ciento de los votos, se colocó como tercera fuerza parlamentaria con 31 escaños de un total de 157. Son estos resultados, así como la polarización y las presiones de la Embajada de Estados Unidos para evitar el ascenso del MAS, los que abrieron la posibilidad de que el MNR y el MIR armaran una difícil coalición parlamentaria y gubernamental, inicialmente con 78 escaños o el 49,67 por ciento del Congreso -casi la mayoría absoluta de 79 escaños- para luego obtener la mayoría absoluta con el apoyo de UCS (83 escaños o el 52,85 por ciento del total de escaños). Por lo tanto, las elecciones de 2002 no desbarataron el sistema de partidos ni dieron lugar a otro eje político alternativo con capacidad de acceder al gobierno. Sin embargo, el porcentaje de escaños del MNR y el MIR, como columna vertebral de la nueva coalición, significaba ya un serio debilitamiento de los partidos relevantes y de las

3 Un sistema de partidos puede suffir transformaciones por distintos razones: por alteraciones del entorno social, por cambios en los patrones de competencia interpartidaria, por modificaciones de la estructura organizativa de los partidos, y por desaparición y/o surgimiento de los partidos que lo componen. 
La crisis del sistema de partidos políticos

en Bolivia: causas y consecuencias

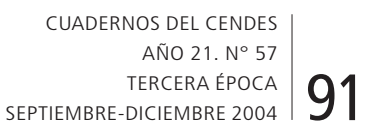

coaliciones gobernantes si las comparamos con anteriores coaliciones como el Pacto por la Democracia en 1985 entre MNR y ADN, que tuvo el 75 por ciento (119 escaños), o el Acuerdo Patriótico en 1989 entre el MIR y ADN que logró el 60 por ciento (94 escaños).

El sistema de partidos sufrió también una sustancial modificación porque los dos partidos neopopulistas que surgieron a fines de la década de los ochenta se hundieron: UCS pasó a la marginalidad al obtener sólo el 5,5 por ciento de los votos y 5 escaños, y Condepa -un patético caso de muerte anunciada- colapsó totalmente con apenas el 0,36 por ciento de los votos, perdiendo así su personería jurídica. Para tres de los cinco partidos importantes desde 1989, las elecciones significaron entonces la tumba o una caída en picada de la cual será muy difícil recuperarse. Por otras dos razones, se puede decir que la recomposición fue igualmente importante. Por un lado, nuevos movimientos campesinos se transformaron en movimientos políticos, logrando una representación política de carácter histórico. El movimiento cocalero, organizado en el MAS, se ubicó en segundo lugar con el 20,94 por ciento de los votos y 35 escaños Si se agrega la votación del MIP, que consiguió el 6,09 por ciento de los votos y 6 escaños, ambos movimientos alcanzaron el 27,03 por ciento de los votos y 41 escaños que constituyen el 26 por ciento del total de escaños en el Parlamento. Por el otro lado, en términos de votos la Nueva Fuerza Republicana (NFR) se ubicó en el tercer lugar con el 20,91 por ciento de los votos, pero, en términos de escaños, en el cuarto lugar. Aunque el número efectivo de partidos se mantuvo inalterable en cuatro, es indudable que el sistema experimentó una notable transformación respecto a los actores que lo componían (cuadro 3).

La segunda consecuencia de gran alcance fue la polarización del sistema multipartidista a causa del surgimiento de movimientos políticos de tendencia fuertemente antisistémica -el MAS y el MIP- y, en menor medida, de la neopopulista NFR. El poder parlamentario logrado por el MAS y el MIP polarizó el sistema de partidos porque ambos se forjaron como movimientos políticos hostiles y/o ambiguos en relación con la democracia representativa y el modelo de economía de mercado. Se abrió así una nueva distancia ideológica con los partidos sistémicos. NFR es parte de este escenario de polarización por ser un partido neopopulista que propone un retorno al sistema de control estatal de la economía.

Estos partidos capturaron el descontento acumulado por la crítica situación de pobreza y exclusión social y por los graves desaciertos del gobierno de Bánzer. El electorado se dividió casi en dos campos al decidirse por ofertas que proponían cambios radicales por la vía del desmontaje radical -aunque no dio su respaldo a otros candidatos antisistémicos como Costa Obregón- o por opciones de reforma moderada. Pero la polarización no fue sólo el resultado coyuntural de la insatisfacción de una parte considerable de la población, especialmente rural, con el rendimiento de los partidos y de la política económica, sino que fue también un efecto del resurgimiento de tensiones étnico-culturales que estuvieron latentes

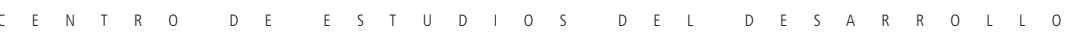


Cuadro 3

Resultados de las elecciones generales del 30 de junio de 2002, por votos y escaños

\begin{tabular}{cccccc}
\hline $\mathbf{N}^{\circ}$ & Partido & Votos & $\%$ & Escaños & $\%$ \\
\hline 1 & MNR & 624.126 & 22,46 & 47 & 29,93 \\
2 & MAS & 581.884 & 20,94 & 35 & $22 ., 29$ \\
3 & NFR & 581.163 & 20,91 & 27 & 17,19 \\
4 & MIR & 453.375 & 16,32 & 31 & 19,74 \\
5 & MIP & 169.239 & 6,09 & 6 & 3,82 \\
6 & UCS & 153.210 & 5,51 & 5 & 3,18 \\
7 & AND & 94.386 & 3,40 & 5 & 3,18 \\
8 & LJ & 75.522 & 2,72 & - & - \\
9 & MCC & 17.405 & 0,63 & - & - \\
10 & PS & 18.162 & 0,65 & 1 & - \\
11 & Condepa & 10.336 & 0,37 & - & \\
\hline \multicolumn{2}{l}{ Votos válidos } & 2.778 .808 & 92,81 & & \\
\hline \multicolumn{7}{l}{ Votos blancos } \\
\hline \multirow{2}{*}{ Votos nulos }
\end{tabular}

Fuente: CNE, elaboración propia.

desde la transición a la democracia y que asumieron ahora una forma política con los movimientos sociales de los cocaleros del Chapare y de los campesinos aymaras del norte de La Paz. Estamos, por cierto, ante la fuerte politización de conflictos económicos y sociales que se desencadenaron en el gobierno de Bánzer, pero, a diferencia de lo que sucedió en el pasado, los movimientos campesinos dieron mayor impulso a las dimensiones étnicoculturales e ideológicas -la democracia comunitaria, el valor cultural-simbólico de la hoja de coca, el rechazo a la economía de mercado y la globalización- que ya estuvieron presentes en la práctica política de Evo Morales desde la formación del movimiento cocalero y su ingreso al Parlamento en 1997. Como reacción a la rígida política norteamericana y a la drástica erradicación de cocales en el gobierno de Bánzer y Quiroga, estos valores y principios fueron explotados crecientemente como dispositivos de justificación ideológica del principal objetivo en la lucha del movimiento cocalero: la defensa de la economía de la coca.

Algunos piensan que han renacido las brechas entre la derecha y una izquierda renovada, y que el MAS es la expresión de una «nueva izquierda». Sin embargo, no se ha producido ni la resurrección de la vieja izquierda marxista ni la emergencia de una 
La crisis del sistema de partidos políticos

en Bolivia: causas y consecuencias

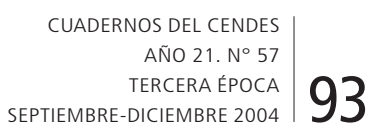

nueva tendencia de izquierda revolucionaria. La izquierda ortodoxa -comunista y trotskista- ha desaparecido del mapa y sus exiguos resabios incrustados en el MAS no son sinónimos de renovación o innovación política. Es cierto que con el MAS y el MIP se han replanteado temas de la izquierda tradicional como el anti-imperialismo, la defensa de los recursos naturales y la recuperación de la economía estatal, pero estos elementos ideológicos son más bien componentes de la izquierda tradicional, conservadora, y no plantean un nuevo modelo económico-social sino la restitución de un modelo populista. Y en el ámbito de las dimensiones étnico-culturales, los programas del MAS y el MIP son también expresiones políticas conservadoras y utópicas que miran hacia atrás. Por esto, estos partidos ponen énfasis en la defensa de tradiciones ancestrales, en la recuperación de territorios originarios y en el futuro político como retorno al mítico pasado del Incario (MAS, 2002:59-88; MIP, 2002:121-134). En ambos sentidos, emplear el término «de izquierda» es inapropiado, a no ser que establezcamos una errónea homología entre este término, el rechazo radical al modelo económico-político y una concepción cíclica de la historia.

La actual polarización ideológica no puede entenderse, entonces, con los parámetros tradicionales de derecha e izquierda porque los conflictos sociales se plantean, sobre todo para el MIP, desde una perspectiva étnico-cultural. Por eso, nuevas contradicciones marcan el actual escenario político y la dinámica del sistema de partidos: contradicciones entre un modelo fundamentalista-étnico y un modelo democrático-pluralista de organización política, entre la democracia del aylluy la democracia representativa, entre un modelo de economía de mercado e inserción en el proceso de globalización y un modelo de economía comunitaria y desarrollo nacional autárquico, entre una concepción del rol del Estado como promotor y regulador de la economía y una concepción de reestatización de la economía.

El tercer efecto de gran relevancia ha sido la inclusión de nuevos sectores sociales en el sistema político. Dadas las características del sistema electoral de doble circunscripción y representación proporcional personalizada que se aplica desde 1997, el sistema democrático demostró tener una gran capacidad de inclusión y adaptación política a las nuevas tendencias y demandas sociales. Si comparamos con intentos previos realizados por partidos kataristas, tanto fundamentalistas como moderados, en la década de los ochenta, es indudable que la lucha por la representación política autónoma de la masa indígena y campesina dio un salto cualitativo, cuya sustentabilidad está, sin embargo, por verse. Por diversas razones, los partidos kataristas nunca habían superado antes el 2 por ciento de la votación. El salto cualitativo en las elecciones de 2002 respondió a dos tendencias de acumulación política de largo alcance que fueron desarrollándose en la última década, particularmente a partir de la reforma electoral de 1994-1996, que impulsa la territorialización del voto, y de la aplicación de la ley de participación popular que ha creado nuevos espacios de competencia políica en el ámbito local-municipal. En primer

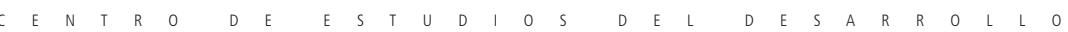


lugar, y en contraste con anteriores elecciones, grandes sectores campesinos e indígenas participaron votando por opciones propias como el MAS y el MIP, fortaleciendo la tendencia hacia una representación político-partidaria autónoma basada no sólo en demandas económico-sociales, sino en la politización del principio de identidad étnico-cultural. En segundo lugar, se ha producido un notable desarrollo de la representación política en la dimensión de la representatividad, es decir, se abrió paso la representación «descriptiva» que satisface el requisito de semejanza, por el cual un sector social o étnico-cultural tiende a elegir representantes que reflejan sus propias características sociales y culturales. De este modo, en las elecciones de 2002 los campesinos aymaras eligieron a representantes aymaras o los cocaleros del Chapare a sus dirigentes sindicales. El otro aspecto decisivo ha sido que los movimientos indígenas desarrollaron la capacidad de transformar su fuerza de movilización social en poder político e ingresar al sistema político-institucional. Por consiguiente, las elecciones no sólo han sacado a la superficie el potencial político de estos movimientos sociales: han robustecido también la lucha de pueblos indígenas por una representación política propia. ${ }^{4}$

Lo notable es que tanto el sistema electoral como el de partidos políticos no se cerraron al acceso de nuevas fuerzas sociales. Ambos desplegaron más bien la flexibilidad suficiente para canalizarlas por un cauce político permitiendo claramente que movimientos sociales e identitarios pudieran transformarse en movimientos políticos con representación propia. ${ }^{5}$ Fue decisiva para esta apertura la reforma electoral realizada entre 1994 y 1996, mediante la cual los partidos políticos intentaron resolver una serie de problemas que afectaron la representación política y el funcionamiento del sistema de partidos. Para contrarrestar el creciente divorcio entre electores y elegidos y hacer posible una cierta autonomía de los diputados frente a las organizaciones partidarias con la representación territorial se introdujo la diputación uninominal. Pero ya en las elecciones de 1997, en las que se aplicó por primera vez, el nuevo sistema electoral de representación proporcional personalizada para la elección de diputados, que combina distritos plurinominales y distritos uninominales, demostró que sus efectos principales no radicaban tanto en la disminución de la desconfianza hacia los partidos o en la reducción del número de partidos políticos y de la volatilidad electoral. Sus efectos más contundentes -y mucho más aún en las elecciones generales de 2002- fueron la territorialización del voto, el perfil del diputado uninominal como gestor de políticas municipales, el reforzamiento de los partidos o movimientos con

4 En el Ecuador surgió también hace pocos años un fuerte movimiento indígena, la Confederación de Nacionalidades Indígenas del Ecuador (Conaie) y su brazo político Pachakuti, que tuvo una fuerte influencia política pero sin lograr una representación parlamentaria similar a la del MAS.

5 Por si fuera poco, esta capacidad de inclusión ha revelado adicionalmente cuán superflua y perniciosa es la modificación adoptada en la reforma constitucional de febrero de 2004 que incorpora la cláusula de que «agrupaciones ciudadanas»y, peor aún, «pueblos indígenas» puedan postularse directamente en elecciones presidenciales y municipales. 
La crisis del sistema de partidos políticos

en Bolivia: causas y consecuencias

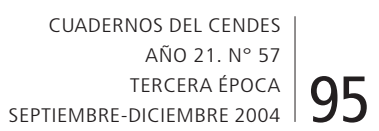

fuertes baluartes locales, así como el fortalecimiento de la representación corporativa y étnica (Mayorga, 2001b, 2001d). Precisamente movimientos políticos como el MAS y el MIP sacaron muchas ventajas del sistema electoral incorporando a sus listas de candidatos a dirigentes indígenas con fuerte presencia en sus distritos rurales, demostrando que el sistema electoral tiene un potencial nada despreciable para promover la dimensión étnica de la representación.

Estimulado así por el sistema electoral, el viraje cualitativo del sistema democrático residió principalmente en la politización del pluralismo multiétnico y multicultural. Sin embargo, no es menos cierto que con este giro se destaparon discrepancias conceptuales y normativas sobre la democracia que anidan hace tiempo en el sistema político y que están en la raíz de la polarización entre dos vías contradictorias e incompatibles: una de ruptura con el sistema democrático, propuesta por corrientes fundamentalistas en el MAS y el MIP, y una de democracia multicultural centrada en el reconocimiento de las diversas identidades étnico-culturales dentro del contexto constitucional y normativo del sistema democrático-representativo. Ambos caminos expresan diferencias culturales y normativas que reproducen una fractura política que el sistema político había empezado a conciliar de manera democrática, aunque muy limitada, con la ley de participación popular y la ampliación de la participación política al campo parlamentario. Sin embargo, estas iniciativas históricas de complementación de dos concepciones diversas de organización política, que podrían convivir con mayores probabilidades de éxito en el ámbito local y municipal, hicieron crisis porque la política de la participación popular en un contexto de grandes limitaciones económicas, sociales e institucionales -especialmente en los municipios andinos- fue desvirtuada por el prebendalismo de los partidos políticos, exacerbándose así las tensiones étnico-culturales. De esta manera, tanto la inclusión de amplios sectores indígenas y campesinos en el sistema político, como la ampliación de la participación política corren el riesgo de naufragar, ante las debilidades institucionales del Estado y de los partidos políticos.

Es en este contexto que el MAS y el MIP surgieron como movimientos identitarios, definiendo su acción política y movilización según la lógica de la «demarcación étnica de límites» (Eder, 2001:202). Estos movimientos comenzaron a explotar políticamente códigos discursivos insertos en el principio de la defensa de identidades colectivas indígenas para refundar el sistema político. Como vimos, entre estos códigos están principalmente la democracia del ayllu, la hoja de coca como símbolo cultural, la idea de la apropiación y el control integral de «territorios originarios», y sobre todo la recuperación de un pasado indígena considerado como época de oro.

Finalmente, el cuarto efecto importante de las elecciones de 2002 tiene que ver con la redistribución territorial y regionalización del voto. Aunque el MNR y, en menor medida, el MIR fueron los partidos con mayor proyección nacional, se dibujó, como nunca antes,

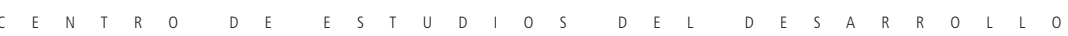


una geografía electoral por la cual la representación política se escindió territorialmente en dos grandes regiones. Las manifestaciones más contundentes de esta fractura fueron, por una parte, el triunfo del MAS por mayoría relativa en cuatro de los cinco departamentos andinos donde está concentrada la población indígena y donde la volatilidad electoral fue especialmente alta en el pasado (La Paz, Oruro, Cochabamba y Potosí) y, por otra parte, la victoria del MNR también por mayoría relativa en los departamentos orientales y amazónicos (Santa, Cruz, Beni y Pando) y el triunfo aislado del MIR en Tarija. Por tanto, la volatilidad electoral se reflejó de manera notoria en una abrupta redistribución territorial del voto. Cabe suponer, por ejemplo, que en el departamento de La Paz los sectores sociales que votaron en elecciones pasadas por Condepa decidieron ahora su voto por el MAS y el MIP, que conquistaron juntos 15 de los 34 escaños adjudicados al departamento.

Las elecciones de 2002 dieron lugar entonces a un sistema con partidos de desigual fuerza y presencia regional; fenómeno que ha sido reforzado por dos razones principales. El sistema electoral de doble distrito impulsa, en efecto, la territorialización del voto en torno a partidos o movimientos que tienen bastiones electorales locales y/o regionales. Hay que considerar, además, que la elección por nueve distritos departamentales con sistemas electorales distintos para la elección de diputados y senadores ha creado una extraordinaria desproporcionalidad territorial del voto -o malapportionment en la terminología de los estudios electorales- que es de las más altas en Latinoamérica y en el mundo (Samuels y Zinder, 2001). Es decir, el principio de la igualdad del voto ha sido vulnerado porque el voto de un ciudadano en Pando vale mucho más que en La Paz o en Santa Cruz. Por ejemplo, en las elecciones de 2002, para elegir un diputado plurinominal en Pando se necesitaba 3.270 votos y en La Paz 28.377 votos. Este es un problema que exige una nueva redistribución del número de diputados por departamento de acuerdo al crecimiento demográfico o la creación de un distrito nacional para la elección de diputados por listas partidarias.

\section{Repensando la representación política y la institucionalización del sistema de partidos políticos}

Las elecciones generales de 2002 desnudaron problemas estructurales que arrastraban los partidos políticos, particularmente en relación con su capacidad de representación. Un problema fundamental fue la volatilidad electoral. Los partidos defraudaron a vastos sectores de la población, provocando expectativas y esperanzas crecientes en nuevos líderes. ${ }^{6}$ Como

6 Por esta razón, el potencial del populismo sigue siendo grande, aunque limitado a sectores pobres que votaron durante una década por Condepa y UCS y en 2002 viraron hacia el MAS, el MIP y NFR. No obstante, la insatisfacción con los partidos políticos tradicionales y el desencanto con la política fueron fenómenos relativos hasta hace poco porque la sociedad no había asumido mayoritariamente posiciones antipartido y antidemocráticas. 
La crisis del sistema de partidos políticos

en Bolivia: causas y consecuencias

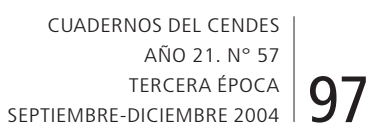

señalan los resultados de las siete elecciones presidenciales realizadas desde 1979, los nexos entre los partidos y la sociedad, reflejados en el apoyo electoral, fueron frágiles. El voto fue sobre todo la expresión de un apoyo condicional, dependiente de la personalidad de los candidatos y del desempeño efectivo de los partidos en función de gobierno en relación con demandas e intereses específicos como empleo, educación, ingreso y vivienda. En principio, no se puede afirmar que el electorado hubiera estado definido por fuertes identidades políticas, sino por la disponibilidad política de amplios sectores pobres de la sociedad. En efecto, para vastos sectores sociales no fueron las alternativas políticas ofrecidas por los partidos políticos lo que realmente importaba, sino la probabilidad de que éstos tuvieran la capacidad de resolver los problemas cotidianos de la gente. Por lo tanto, la volatilidad electoral se originó en dos causas estructurales: por un lado, en el desgaste de los partidos en función de gobierno a raíz de su insuficiente capacidad para obtener una «legitimación por rendimiento» mediante políticas públicas eficaces; por el otro lado, en transformaciones profundas de la estructura social que tienen que ver con el crecimiento de la economía informal y la desaparición de la economía estatal, y que erosionaron las bases sociales de lo partidos y, en consecuencia, la representación política.

Los partidos políticos no tuvieron electorados permanentes, ubicados en una determinada clase social, si bien los más relevantes montaron bastiones regionales bastante estables. A partir de la crisis de la economía estatal, que llevó a la disolución de la clase obrera, los partidos importantes tendieron a actuar como catch-all parties buscando representar a diversas clases o segmentos sociales sin apelar directamente a algún grupo social determinado o a una ideología clasista. Como resultado, tanto para ellos como para sus electorados, las demandas políticas se transformaron en demandas negociables y su racionalidad de acción fue, por esta razón, pragmática. En Bolivia se ha reproducido así un fenómeno que es mundial: la transformación de la naturaleza de la representación política misma impuso un carácter fluido y funcional a los apoyos electorales.

Sin electorados estables, los partidos se vieron sometidos a fuertes oscilaciones y desplazamientos de las preferencias electorales cuya consecuencia directa fue precisamente la volatilidad electoral. Tomando en cuenta las elecciones presidenciales y de diputados entre 1979 y 1993, la volatilidad media en Bolivia fue de, 36,1 por ciento, relativamente baja comparándola con la volatilidad media del Perú (54,2 por ciento) y la del Brasil (70 por ciento) en períodos similares. Son los sectores informales los que han demostrado un enorme grado de fluctuación de sus preferencias electorales, lo cual evidencia también que no estuvieron ligados a los partidos políticos por razones ideológicas o programáticas. Con las excepciones parciales de Condepa y actualmente del MAS, los partidos políticos no tuvieron un arraigo en sectores sociales específicos. Así, por ejemplo, los sectores de clase media, que entre 1979 y 1989 votaron preferentemente por ADN, desplazaron su apoyo

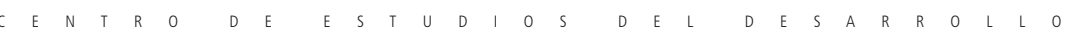


en 1993 hacia el MNR y en 1997 y 2002 volvieron en cierta medida a apoyar a ADN y al MIR, y luego al MNR y al MIR respectivamente. De los partidos creados en los últimos años, quizás sólo el MAS, que es en el fondo un movimiento social, tenga alguna posibilidad de transformarse en un partido con convocatoria estable, aunque restringida regionalmente a la región andina del país, mientras que la NFR ha demostrado ser un partido frágil cuyo crecimiento a escala nacional fue más aparente que real. Después de la crisis de octubre de 2003, no hay elementos para sostener que el ascenso logrado por la NFR en las elecciones de 2002 con un programa populista y demagógico pudiera traducirse en una alternativa frente al decaimiento de los partidos que fueron el eje del sistema político.

¿Refleja la inestabilidad de la representación política una frágil y embrionaria institucionalización del sistema de partidos? Mainwaring y Scully han planteado cuatro criterios efectivos para diferenciar los niveles de institucionalización de los partidos políticos en América Latina: 1) la estabilidad en las reglas de juego y el fortalecimiento de la competencia interpartidaria; 2) la existencia de partidos con fuertes raíces en la sociedad; 3) la legitimidad acordada por los actores políticos al proceso electoral y los partidos; y 4) la existencia de organizaciones partidarias bien establecidas (Mainwaring y Scully, 1995:46). Con base en estos criterios, estos autores clasifican el sistema de partidos de Bolivia, junto con el de Ecuador y Brasil, como embrionario. En contraste, y aplicando los mismos criterios, se podrían evaluar de una manera más positiva los niveles de institucionalización que relativamente alcanzó el sistema de partidos en Bolivia hasta 2002, por lo menos en tres aspectos. En primer término, el sistema de partidos fue exitoso en crear una relativa estabilidad de las reglas de juego y fortalecer la competencia entre las organizaciones políticas. Si no fuera así, el sistema de partidos no habría desarrollado la capacidad de acuerdos y de formación de gobiernos estables de coalición. En segundo término, a pesar de la grave erosión que sufrió el sistema partidista en las elecciones de 2002, dos partidos -el MNR y el MIR- mantuvieron todavía su arraigo relativamente estable en la sociedad, como se demuestra por la votación obtenida entre 1985 y 2002. En tercer término, no obstante el rechazo de muchos dirigentes del MIP y del MAS -ahora parlamentarios-a la «democracia burguesa», las reglas de juego y la legitimidad de los procesos electorales no fueron cuestionadas.

Es en relación con el cuarto nivel de institucionalización que persistieron y persisten serias dudas, especialmente por los resultados de las elecciones de 2002. Con la excepción my parcial del MNR y el MIR, los partidos y nuevos movimientos políticos carecen de sólidas organizaciones y de estructuras internas (Mayorga, 2002:167-213). Este es, en efecto, el aspecto más controvertido y desigual. Impulsado por la ley de partidos políticos y la ley electoral, se inició tardíamente en 1999 un proceso de democratización interna de los partidos que se estancó en una fase embrionaria. Sin definir taxativamente cuáles 
La crisis del sistema de partidos políticos

en Bolivia: causas y consecuencias

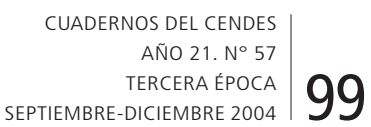

deberían ser en concreto las normas y procedimientos, los artículos 19 y 20 de la Ley de Partidos Políticos exigen a los partidos de modo general el ejercicio de la democracia interna, estableciendo normas de elección y nominación de candidatos que garanticen la organización y el funcionamiento democrático de estas organizaciones. Esto me parece razonable porque se ha evitado imponer el sistema de primarias imperante en EE UU que ha tenido consecuencias muy negativas sobre los partidos (Dahl, 1990; Lijphart, 1999). Lo menos que se puede afirmar es que las primarias no favorecen necesariamente la democratización de los partidos.?

Sin embargo, el proceso de democratización interna tuvo, por muchas razones, resultados muy limitados y discutibles. Fue una constante demanda de la sociedad, pero cobró impulso recién por las transformaciones que trajo consigo la Ley de Participación Popular, elevando el municipio a una categoría de primer orden del escenario político antes desconocida. Las organizaciones partidistas se vieron en la necesidad de adecuar sus estructuras a los nuevos espacios locales. Dada la flexibilidad de la Ley de Partidos Políticos, los procedimientos y los alcances de la democratización interna fueron diferentes. Una primera diferencia radicó en los alcances de las elecciones internas: es decir, si se debía elegir a todas las autoridades del partido, incluyendo al jefe nacional. La otra diferencia consistía en el carácter abierto o limitado de las elecciones; es decir, si los ciudadanos con derecho a voto debían ser sólo los militantes o también los simpatizantes o simplemente cualquier ciudadano como en EE UU. El MNR realizó las elecciones internas en julio de 1999, antes de la promulgación efectiva de la Ley de Partidos Políticos en agosto de ese año. De acuerdo con sus estatutos, el MNR estableció procedimientos para la elección directa de los dirigentes, abarcando todos los órganos de dirección nacional y territorial del partido, como son la Convención Nacional (compuesta por 642 delegados territoriales y 100 delegados funcionales y sectoriales), el Comando Nacional (compuesto por 100 delegados territoriales y 20 delegados funcionales y sectoriales) y el Comité Ejecutivo Nacional -el máximo órgano de dirección- que está conformado por el jefe nacional, 2 subjefes nacionales, 9 jefes departamentales y 9 delegados electos por el comando nacional y el secretario ejecutivo. De este proceso se exceptuó al jefe nacional del partido, cuya elección sigue siendo una atribución de la Convención Nacional. El derecho a voto fue ejercido principalmente por los militantes, pero fue ampliado a los simpatizantes, quienes en el momento de elegir a sus candidatos debían firmar su adhesión al partido.

Comparando las tres elecciones internas de los partidos realizadas entre 1999 y 2001, es claro que el único que logró democratizar de manera limitada sus estructuras internas y además renovar sus órganos de dirección fue el MNR. Aunque hubo también

${ }^{7}$ Discrepo en este aspecto de la interpretación muy positiva de Daniel Zovatto acerca de las funciones y los efectos democratizadores de las primarias (Zovatto, 2000:2).

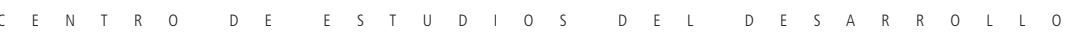


irregularidades en los comicios, éstas no fueron de una gravitación negativa. Por el contrario, en términos generacionales y de renovación, estas elecciones tuvieron cierta importancia porque llevaron a la derrota de la llamada «guardia vieja» y al ascenso de nuevos dirigentes a niveles de decisión en el partido, particularmente en los órganos claves que son el Comando Nacional y el Comité Ejecutivo Nacional. De los partidos históricos, cabe recordar además que hasta ahora sólo el MNR logró reemplazar a su «jefe histórico», Víctor Paz Estenssoro (1942-1988), quien fue sustituido por Sánchez de Lozada en 1989. No obstante, las elecciones internas dejaron profundas heridas entre los sectores antiguos y nuevos del partido, así como recelos entre los nuevos dirigentes que no quedaron satisfechos con las funciones asumidas después de la Convención Nacional que reeligió a Sánchez de Lozada como jefe de la organización. Las elecciones internas tampoco tuvieron impacto sobre la democratización del MNR en relación con el desarrollo de prácticas de debate colectivo y con la conducción democrática del partido. Sánchez de Lozada se erigió y se mantuvo como caudillo indiscutido que impuso sus ideas y objetivos.

En el MIR y ADN las elecciones internas tuvieron alcances diferentes y fueron realizadas con muchos sobresaltos y vicios. Estuvieron empañadas por graves dudas sobre la legitimidad de los procedimientos utilizados, como compra de votos y violación de las normas democráticas, y por acusaciones severas entre los candidatos, especialmente, entre candidatos a jefes departamentales. El caso del liderazgo del MIR, un partido que se concibe como socialdemócrata, es el más insólito, considerando sus prácticas políticas que han contradicho insistentemente su retórica democrática. Desde su fundación en 1971 es un partido altamente caudillista que hasta hace poco carecía de estatutos internos y no llevó a cabo un congreso partidario. Ha sido y es un partido dependiente en extremo de su líder máximo, Jaime Paz Zamora, que resolvió sus disputas internas por la vía de la expulsión o autoexclusión de los disidentes. Sus dirigentes en el nivel del Comité Ejecutivo Nacional fueron designados directamente por el jefe del partido. Sus patrones de acción han obedecido a las normas tradicionales del clientelismo y prebendalismo, lo cual se ha puesto de manifiesto claramente en varios departamentos del país en donde sus lideres regionales -los denominados «cardenales»- actuaron como caciques de antaño.

Las elecciones internas del MIR de 2001, abiertas a cualquier ciudadano que quisiera votar y limitadas a la elección de jefes departamentales, fueron cuestionadas en ciudades importantes como Santa Cruz y La Paz, donde se decidió anularlas por el exceso de actos fraudulentos (como manipulación de registros), provocando además serias fracturas y peleas internas entre los «cardenales» y los llamados renovadores, que se lanzaron mutuamente acusaciones de manipulación electoral y compra de votos. En el caso del MIR, es aún más difícil afirmar que las elecciones internas hubieran promovido la democratización interna ni menos una renovación legitimada de los liderazgos, a pesar de que en varias regiones 
del país aparecieron nuevos líderes del partido. Éste emergió de su proceso electoral con mayor dependencia aún de su líder y sin haber saldado seriamente cuentas con varios dirigentes comprometidos desde hace muchos años en flagrantes casos de corrupción.

En ADN las elecciones internas no fueron menos cuestionables. Éstas se realizaron para elegir a los jefes departamentales, estando restringido el derecho de voto a sus militantes. Pero, como en el caso del MIR, hubo problemas escandalosos de transparencia en los procedimientos. Las elecciones en La Paz fueron anuladas por la propia junta departamental del partido y las de Potosí por la Corte Nacional Electoral. En Cochabamba el prefecto departamental, miembro de ADN, fue acusado de utilizar recursos humanos y financieros del gobierno regional para ganar las elecciones, razón por la cual miles de militantes optaron por renunciar al partido. En ADN es evidente que el intento de democratización interna resultó frustrado porque no se legitimaron las dirigencias regionales con procedimientos claros -los propios dirigentes violaron sus estatutos internos y las normas institucionales-y la renovación de liderazgos quedó entrampada en la lucha interna entre los grupos modernizadores y tradicionales del partido. ADN, como en el caso del MIR, continuó siendo un partido altamente dependiente de su líder, el general Bánzer. Las elecciones internas no despejaron las sospechas fundadas de que Bánzer, como cabeza entonces del Poder Ejecutivo, apoyó de manera preferente ciertos candidatos. ${ }^{8}$

Resumiendo, el balance que se puede hacer de los primeros intentos de democratización interna entre 1999 y 2001 resulta muy pobre. Sólo en el caso del MNR llevó a una cierta democratización y renovación de estructuras y liderazgos regionales y locales, mientras que en el MIR y ADN los procedimientos ilegítimos y las fracturas internas entorpecieron ambos objetivos. En los tres casos la democratización tuvo en común una serie de conflictos que pusieron en entredicho, en mayor o menor medida, la cohesión de los partidos y la aceptación de corrientes divergentes internas. ${ }^{9}$ Fue notorio sobre todo que la democratización interna no tuviera ninguna relevancia para fortalecer a los partidos haciendo de los nuevos dirigentes líderes representativos de la sociedad.

\section{¿Crisis de descomposición y colapso del sistema de partidos?}

No obstante la volatilidad electoral y las enormes deficiencias de los partidos como organizaciones, el sistema de partidos pudo desarrollar un grado notable de estabilidad política, basada en acuerdos y gobiernos de coalición, hasta 2000. En una etapa crítica

8 En un segundo intento después de la muerte de Bánzer y antes de las elecciones de 2002, ADN realizó elecciones primarias, abiertas a cualquier ciudadano, que incluyeron la elección del nuevo jefe del partido, Jorge Quiroga, y del candidato presidencial, y que no pudieron evitar su catastrófica derrota electoral.

9 Se confirma la tesis de Lijphart de que las primarias desencadenan una competencia interna entre candidatos que exacerban los conflictos internos, sufriendo así la unidad y cohesión de los partidos. Lijphart sostiene que las elecciones primarias al estilo norteamericano debilitan seriamente a los partidos, privándolos de su función más importante, que es nominar a los candidatos a cargos públicos (Lijphart, 1999:6). 
para la supervivencia de la democracia como fue el gobierno de la UDP, los liderazgos políticos tuvieron la capacidad de adaptación a los nuevos problemas que planteaba la necesidad de crear condiciones necesarias para la estabilidad y gobernabilidad del país. Desarrollaron estilos más adecuados al desarrollo democrático, como la flexibilidad política, la capacidad de compromiso y búsqueda de consensos. ¿Cómo explicar entonces la profunda crisis actual del sistema de partidos políticos? ¿Qué causas estructurales y/o coyunturales están en la raíz de este proceso de involución? Sin suponer un enfoque determinista, pienso que una explicación satisfactoria debe combinar factores causales, tanto estructurales como coyunturales, que empezaron a manifestarse en el gobierno de Bánzer (1997-2002) y finalmente hicieron explosión en la gran crisis que sobrevino después de las elecciones presidenciales y parlamentarias de 2002. El débil gobierno de coalición de Sánchez de Lozada nació determinado por la polarización y el bloqueo entre Parlamento y Ejecutivo: las dos consecuencias de carácter coyuntural más importantes en las que se condensaron aquellos problemas y limitaciones que los partidos políticos fueron acumulando y no pudieron superar a lo largo de la década de los noventa.

Una primera causa con implicaciones graves fue que las coaliciones gubernamentales llegaron a convertirse en mecanismos insuficientes de gobierno, provocando la desnaturalización y desaparición del concepto y práctica de una oposición parlamentaria crítica y responsable. Similar a las experiencias de concertación y consenso entre partidos en la Colombia del Frente Nacional y en la Venezuela del Pacto de Punto Fijo, la política boliviana fue, en efecto, una política de acuerdos entre los lideres máximos de los partidos, algo así como una "conversación entre caballeros». Los partidos se habían afirmado como sujetos fundamentales de la política dentro del contexto institucional que definí como «democracia pactada» y «presidencialismo parlamentarizado» (Mayorga, 1991, 2001c). Pero este tipo de democracia pactada decayó, generando un estilo de hacer política hermético y prebendalista, así como un serio aflojamiento de los nexos de los partidos con la sociedad civil.

Una segunda causa es la transformación de los partidos, de mediadores entre el Estado y la sociedad en actores integrados al poder estatal, que se produjo simultáneamente con la estabilidad política lograda. Es decir, la creciente penetración entre el Estado y los partidos implicó que todos los partidos importantes del sistema compartieran los recursos del Estado. Dado el control irrestricto de las instituciones estatales por las organizaciones partidistas, el sistema de partidos se volvió autorreferente y de autoservicio; en el fondo, un sistema de partidos-cartel. ${ }^{10}$ Gobiernos estables de coalición transformaron el Estado

${ }^{10}$ Katz y Meier desarrollan el concepto de partidos-cartel para explicar sistemas de partidos que han invadido el Estado y lo convierten en una estructura institucionalizada de respaldo partidario. De esta manera, una fuerte interpenetración entre Estado y partidos permite que éstos sobrevivan conjuntamente compartiendo los recursos estatales (Katz y Meier, 1995:16). 
La crisis del sistema de partidos políticos

en Bolivia: causas y consecuencias

\author{
CUADERNOS DEL CENDES \\ AÑO 21. N 57 \\ TERCERA ÉPOCA \\ SEPTIEMBRE-DICIEMBRE 2004 \\ 103
}

en una estructura de incentivos y beneficios que absorbió a los partidos relevantes y pequeños. De forma paralela, los partidos se transformaron en máquinas electorales y agencias de distribución de cargos públicos y apropiación de recursos estatales, desprendiéndose de sus referentes ideológicos y programáticos y relegando sus funciones de articuladores entre la sociedad y el Estado. No pudieron ni quisieron percibir la necesidad de establecer nexos más complejos y creativos con la sociedad civil.

La tercera causa reside en que esta doble transformación de los partidos políticos remató en un modelo hermético de gobernabilidad y en la deformación de la política de acuerdos interpartidarios como principio de formación de gobiernos de coalición. Intereses particularistas se fueron imponiendo sobre objetivos programáticos en las políticas gubernamentales. El modelo de gobernabilidad se desfiguró en los dos últimos gobiernos con el mero clientelismo y la repartición de cargos, desplazando a segundo lugar los aspectos programáticos y la política de negociación con las organizaciones sociales. Por otro lado, los pactos políticos no se ampliaron a pactos sociales y, al final, los gobiernos de coalición con amplia mayoría parlamentaria terminaron suspendidos en el vacío. Los partidos dejaron de ser mecanismos eficaces de agregación y canalización de demandas y conflictos sociales y, sobre todo, mediadores entre la sociedad y el Estado. Como consecuencia, los gobiernos de coalición y las mayorías parlamentarias dejaron también de ser gestores de políticas públicas eficaces quedando inermes ante la ofensiva de los nuevos movimientos sociales indígenas y otras organizaciones sociales. La política se redujo al manejo mezquino del poder de facciones y camarillas carentes de visión de gran política ni de Estado. Fue sinónimo de vulgar negocio y de acceso al empleo para desocupados de diversos sectores sociales y, por supuesto, de enriquecimiento ilícito. El resultado perverso y negativo para la legitimidad democrática fue que los partidos que tuvieron responsabilidad de gobierno dilapidaron su capital político, corrompieron la política y, al final, desvirtuaron la democracia pactada.

La cuarta causa consiste en procesos de democratización interna que no alteraron el control caudillista de los líderes sobre las organizaciones partidarias. Se hizo evidente la contradicción aún imperante entre el sistema multipartidista competitivo y la organización interna antidemocrática de la mayoría de los partidos. La renovación regional y local de los partidos, en gran medida por presiones desde abajo ligadas a la ley de participación popular, no abrió suficientemente los cauces necesarios para lograr un impacto en las direcciones nacionales de los partidos.

Se puede identificar también una quinta causa estructural que explica el declive de los partidos políticos: las deficiencias de su organización interna repercutieron en la importante dimensión de la calidad del liderazgo político, que no sólo no se pudo elevar, sino que fue descendiendo dramáticamente a niveles de incompetencia e irresponsabilidad.

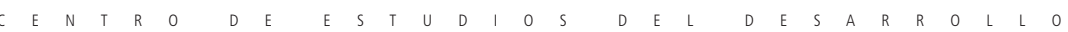


Como lo demuestran los gobiernos de Bánzer (1997-2002) y Sánchez de Lozada (6/8/ 2002-17/10/2003), los líderes gubernamentales no estuvieron a la altura de la complejidad de los problemas económicos y sociales que enfrenta el país y menos tuvieron la capacidad para resolver conflictos y negociar acuerdos con los actores sociales. Gran parte de la clase política no logró desarrollar la competencia profesional de sus cuadros de dirección, lo cual incidió negativamente en la capacidad de gestión gubernamental. La aplicación del nuevo sistema electoral para la elección de más de la mitad de los diputados en distritos uninominales fue también una causa adicional significativa: fortaleció la representatividad del sistema político y llevó a la renovación del 70 por ciento de la Cámara, pero tuvo efectos negativos al reducir los ya bajos niveles de profesionalización de los parlamentarios. Los diputados por distritos uninominales son más representativos, pero mucho menos competentes (Mayorga 2000). La crisis de los partidos se refleja, en consecuencia, como una grave crisis de liderazgo político sin alternativas visibles de renovación en el momento histórico actual. En la crisis de octubre de 2003, gran parte del liderazgo político dejó de ser adecuado y funcional para asegurar la viabilidad y la continuidad del sistema democrático. Si la democracia política es un «método competitivo de reclutamiento de lideres» (Sartori, 1988:198), hay muchas evidencias de que, por lo menos en la última década, en Bolivia no ha servido suficientemente a tal efecto."

Una sexta causa reside en el carácter limitado del proceso de modernización del Estado. Las prácticas patrimonialistas de los partidos vulneraron y erosionaron los avances institucionales de la democracia. Esto suena a paradoja, porque Bolivia fue considerada en el panorama latinoamericano como unos de los países reformadores más agresivos y como un «show case» por la aparente y feliz convergencia del ajuste estructural y el rediseño de las instituciones políticas. Sin embargo, la crisis actual del Estado desnuda claramente los límites del proceso de institucionalización. De hecho, no pudo cristalizar una política coherente y sostenida de modernización y construcción estatal al imponerse un estilo de institucionalización perversa; es decir, un proceso de reformas institucionales deformado por las prácticas patrimonialistas de los partidos. Las diversas reformas institucionales (participación popular, descentralización, reforma del poder judicial, etc.) fueron contradichas y contrarrestadas por intentos reiterados para conservar simultáneamente cotos reservados de control partidario, de prebendas y beneficios. Es decir, las nuevas instituciones no fueron suficientemente acompañadas ni reforzadas por cambios en los comportamientos y prácticas tradicionales de los liderazgos y partidos ni por la reorganización de la burocracia estatal de acuerdo a criterios de eficacia y competencia. Hay muchos argumentos para afirmar que la modernización del Estado fue en varios campos ficticia y que hubo, por el contrario,

11 La calidad del liderazgo -calidad en términos de conocimiento, visión, capacidad de concitar apoyo social y dirigir a la sociedad, competencia profesional, responsabilidad autónoma- es un problema central de la democracia boliviana, un problema generalizado en las democracias contemporáneas, pero con consecuencias desastrosas en un país pobre. 
La crisis del sistema de partidos políticos

en Bolivia: causas y consecuencias

\author{
CUADERNOS DEL CENDES \\ AÑO 21. N 57 \\ TERCERA ÉPOCA \\ SEPTIEMBRE-DICIEMBRE 2004

una seria erosión del Estado porque las reformas fueron corroídas por el manejo arbitrario del poder, como ocurrió con la descentralización, minando la capacidad estatal para afrontar demandas económicas y sociales así como para articular políticas de integración nacional.

Por último, es necesario referirse a una causa coyuntural: el estancamiento económico desde 1999, por efecto de la recesión internacional, se reflejó en la caída del crecimiento económico de una tasa promedio del 4 por ciento del PIB en la década de los noventa a un promedio de apenas el 2 por ciento del PIB entre 1999 y 2002. En una economía que sigue atrapada en el modelo tradicional de desarrollo sustentado en la exportación de materias primas de bajo valor agregado, por tanto, una economía vulnerable y dependiente del apoyo externo, las políticas económicas liberales y de fomento de la inversión externa generaron un desarrollo muy desigual de las regiones y de la distribución de ingresos. Además, el descenso de la economía fue agravado por una agresiva política de erradicación de la hoja de coca que tuvo el efecto de una contracción del PIB en un 8 por ciento en los últimos años.

Todos estos factores estructurales y coyunturales aceleraron un proceso de erosión de los poderes del Estado. Su capacidad para decidir sobre políticas públicas y su autoridad para implementarlas fueron seriamente cuestionadas. Se multiplicaron y agudizaron los conflictos sociales y los partidos más importantes del sistema se deslegitimaron en los dos últimos gobiernos de coalición como actores responsables y eficientes de gobierno y gestión estatal; no reaccionaron eficazmente con políticas públicas adecuadas a los problemas del desempleo, la pobreza y la corrupción, al tiempo que -en medio de la degeneración facciosa de la política- se cebaban en el uso predominantemente patrimonialista de los recursos del Estado. En el gobierno de Bánzer se estableció una peligrosa dinámica no mediatizada institucionalmente entre el Estado y la sociedad, creándose un círculo vicioso de movilizaciones, demandas y chantajes de toda naturaleza, frente a los cuales el Gobierno adoptaba la posición de ceder y capitular. Pero no sólo el Poder Ejecutivo se debilitó. ${ }^{12}$ Las demás instituciones del Estado, como el Parlamento y los gobiernos regionales y locales, tampoco pudieron intervenir como articuladores y canalizadores de las demandas y conflictos sociales. En efecto, todas las instituciones principales del sistema democrático se debilitaron de tal manera que lo que empezó como falta de rumbo de la coalición de Bánzer y crisis de la gestión gubernamental derivó progresivamente en una crisis de Estado -que afectó el Poder Ejecutivo, al Parlamento, las Fuerzas Armadas, la policía-y que se prolongó y acentuó en el gobierno de Sánchez de Lozada hasta su derrumbe en octubre de 2003.

${ }^{12}$ A esto contribuyeron políticas y acciones desacertadas: la erradicación radical de la coca impuesta por EE UU sin nada sustancial a cambio, la política represiva contra los cocaleros, la desvirtuación del diálogo nacional, el aumento de la corrupción y la impunidad, la descarnada pelea por el botín del aparato estatal, el intento de recuperar el control de la Corte Nacional Electoral nombrando 41 vocales de las cortes electorales departamentales entre partidarios de la coalición en febrero de 2001.

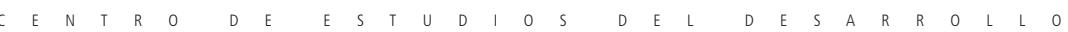


En este efímero gobierno se vislumbraron claramente la decadencia de las coaliciones gobernantes y la parálisis estatal. La coalición de Sánchez de Lozada, enfrascada en el mezquino juego de la distribución de puestos en la administración del Estado, fue incapaz de imprimir cambios necesarios de rumbo a la política y menospreció la capacidad de movilización de movimientos contestatarios, cayendo víctima de la paradoja de un gobierno de coalición con mayoría parlamentaria, pero paralizado en su capacidad de decisión. De hecho, en un escenario de polarización entre el Ejecutivo y la oposición del MAS y de movimientos radicales, el Gobierno no pudo tomar en absoluto ninguna decisión importante ni hacer aprobar o hacer aceptable ninguna ley relevante referida a los temas esenciales -reactivación económica, reducción del déficit fiscal, política de exportación e industrialización del gas, política de la hoja de coca vinculada al desarrollo basada en el desarrollo alternativo. El estrepitoso fracaso del gobierno de Sánchez de Lozada exacerbó entonces la perversa herencia que dejó el de Bánzer: la crisis económica, la bancarrota de la autoridad del Estado, el divorcio Estado-sociedad y el desprestigio de los partidos políticos y el crecimiento de movimientos políticos anti-sistémicos. Y ambos gobiernos marcaron en dos etapas consecutivas un proceso de agotamiento de los partidos relevantes que más parece presagiar el hundimiento del sistema de partidos. En conclusión, factores causales, tanto estructurales como coyunturales, confluyeron en los gobiernos de Bánzer y Sánchez de Lozada determinando un proceso regresivo de ingobernabilidad e incertidumbre.

\section{El experimento del gobierno sin partidos: ¿la cuadratura del círculo?}

El gobierno de Carlos Mesa, un outsider de la política, emergió gracias a que se impuso el mecanismo de la sucesión constitucional en un momento en el que el MAS y las organizaciones sociales que precipitaron la caída de Sánchez de Lozada apuntaban a una interrupción del mandato constitucional por la vía de elecciones anticipadas. Al asumir la presidencia en medio de una crisis sin precedentes, Mesa adoptó dos decisiones de gran gravitación que aferran como tenaza a su gobierno. La primera decisión fue formar un gabinete de independientes, basándose en el supuestamente incontrovertible argumento de que el descrédito y fracaso de los partidos habían desvirtuado y enterrado el ciclo de la democracia pactada y los gobiernos de coalición. La segunda decisión fue asumir la llamada «agenda de octubre», impuesta por el MAS y dirigentes del movimiento insurreccional contra Sánchez de Lozada que, con derivaciones y consecuencias imprevisibles, plantea sobre todo dos objetivos: el referéndum sobre la política del gas y la asamblea constituyente.

¿Eran ambas decisiones, como ahora se tiende a considerarlas, el camino único e ineluctable para afrontar la crisis política? Por sus consecuencias no deseadas y perversas que ya están a la vista, es pertinente abrigar serias dudas. Es cierto que la sucesión constitucional fue la mejor solución posible para la estabilidad democrática, pero la agenda de

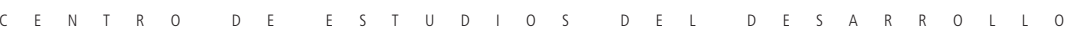


La crisis del sistema de partidos políticos

en Bolivia: causas y consecuencias

\author{
CUADERNOS DEL CENDES \\ AÑO 21. N 57 \\ TERCERA ÉPOCA \\ SEPTIEMBRE-DICIEMBRE 2004

octubre entraña una salida plena de riesgos porque conspira contra esta misma estabilidad y, como resultado de la quiebra de consensos y de la caída del gobierno de Sánchez de Lozada, atiza más el fuego de la polarización y confrontación. La agenda de octubre es el producto de una crisis total de hegemonía, pero es probable que quede entrampada porque no es un programa político con potencial para resolver esta crisis. El proyecto de realizar una asamblea constituyente en un escenario de grave polarización puede significar un salto al vacío, un paso más acelerado hacia el desmontaje de la democracia, pues refuerza tendencias democráticas en apariencia pero devastadoras en sus objetivos y consecuencias, como es la tendencia hacia la democracia plebiscitaria y populista que esta agenda implica, llevando al Gobierno a someterse a presiones corporativas y asambleístas así como a abdicar de su responsabilidad constitucional por políticas de Estado (Mayorga, 2001a). Esta tendencia se manifiesta claramente en el referéndum de carácter plebiscitario que ha propuesto el gobierno en Abril de 2004 y que no disipa las incertidumbres y problemas porque, como astuto intento de equilibrio entre posiciones antagónicas, permite interpretaciones contradictorias.

La decisión de formar un gobierno sin partidos y sin soporte parlamentario constituye también un frágil experimento gubernamental. Subestimando el hecho real de que los partidos políticos son aún factores de poder, el Gobierno no le dio mucha importancia por razones de principio a un trabajo permanente de articulación y concertación política con el Legislativo. El gobierno de Mesa enterró la democracia pactada; sin embargo, su supervivencia depende paradójicamente de la colaboración de los partidos y de la concertación con ellos. ¿Puede un gobierno sin apoyo parlamentario consistente, que ha recurrido a un partido fantasmagórico como el Movimiento Bolivia Libre (MBL), gobernar a espaldas del parlamento y, además, resistir a organizaciones sociales radicales en las que quiso apoyarse y que ahora se le oponen? ¿Es sostenible un régimen político con un Ejecutivo independiente y un Parlamento más hostil que colaborador, en el cual se ha esfumado la división tradicional entre oficialismo y oposición?

Mesa optó resueltamente por correr el riesgo de presidir un gobierno bloqueado en el Parlamento por los partidos depuestos y por la oposición inicialmente virulenta del MAS, y también acosado por el recelo de la embajada estadounidense. En el primer medio año de su gobierno, Mesa, aislado del Congreso, desterró la concertación política confiando en que su imagen y el elevado apoyo de la opinión pública ejercerín la presión necesaria y serían suficientes para realizar la agenda política de octubre de 2003. En el terreno de la propia agenda de octubre, el gobierno de Mesa estuvo paralizado y no pudo cumplir sus promesas respecto al referéndum y la ley de hidrocarburos, que además generaron alarma y suspicacia en los consorcios petroleros. Después de varios intentos fracasados de acercamiento entre el Congreso y el Ejecutivo, el primero pasó a la ofensiva poniendo en

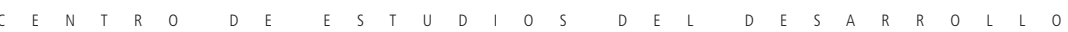


jaque al Gobierno cuando censuró a un ministro y rechazó la política fiscal. Ante esta situación, el Ejecutivo amenazó con la dimisión y Mesa tuvo finalmente que admitir que era «muy difícil cambiar el país sin respaldo político» (La Prensa, 13/3/2004). Recién en marzo de 2004 y después de la fuerte presión ejercida por la embajada de EE UU, tuvo lugar un deshielo parcial cuando el MNR y el MIR sancionaron parcialmente un proyecto de ley para aliviar el elevado déficit fiscal. Mesa decidió sobre todo adoptar un paso firme para romper el cerco de la política enteramente reactiva del Parlamento que rechazó el debate sobre el proyecto de ley de hidrocarburos del Gobierno. Éste lanzó entonces una contraofensiva al convocar al referéndum sobre la política del gas sin una ley previa, lo cual implicaba en principio la decisión de gobernar por decreto y obligar al Parlamento a adoptar una posición.

Bajo estas circunstancias, la viabilidad del Gobierno ha dependido ciertamente de un juego de equilibrios muy inestables con el parlamento y las organizaciones sociales; y si logró mantenerse precariamente se debió en gran parte al cambio de estrategia del MAS, que pasó del «cerco»-aplicado contra Sánchez de Lozada y, al principio, también contra Mesa- a una estrategia de apoyo indirecto y después de limitados acuerdos con el Gobierno, a fin de potenciarse para las elecciones municipales de diciembre de $2004 .{ }^{13}$ Otra razón que explica su ardua supervivencia fue la propia fragmentación y el particularismo de movimientos sociales y «minorías intensas» que se oponen al Gobierno. Siendo promotores de inestabilidad política, ninguno de ellos por sí solo podría derrocarlo, aunque en un posible pero poco probable escenario de caos generalizado y desmoronamiento del Estado, el resultado sería la renuncia de Mesa. Un panorama distinto se presenta en el ámbito de los partidos políticos que, en su mayoría, han apostado por una política ambigua de colaboración con el Ejecutivo porque saben, en el fondo, que la estabilidad del gobierno de Mesa es una condición para enfrentar su crítica situación actual. Sin recursos directos de poder en el Ejecutivo, los partidos ex-gobernantes perdieron liderazgo y cohesión, y están corroídos por la desintegración. El golpe devastador que sufrieron los condenó a parapetarse en un Parlamento convertido -como algunos ámbitos en la administración pública- en último baluarte de acción en el que poseen mecanismos de influencia y decisión. Por otra parte, dado el viraje hacia una estrategia electoral de conquista del poder, el MAS se transformó a regañadientes y con muchas duplicidades en el principal soporte del Gobierno. No obstante, debido a la fragmentación y la polarización de las bancadas parlamentarias, el nuevo posicionamiento del MAS tampoco fue suficiente para superar las tensas relaciones

13 EI MAS apoyó la Ley de Impuestos a las Transacciones a cambio de que el Gobierno renuncie a erradicar coca en los Yungas y paralice la construcción de un retén de control policial. Apoyó también el decreto del referéndum sobre la política de hidrocarburos, aunque no está de acuerdo con la pertinencia y significación de todas las preguntas planteadas. 
La crisis del sistema de partidos políticos

en Bolivia: causas y consecuencias

\author{
CUADERNOS DEL CENDES \\ AÑO 21. N 57 \\ TERCERA ÉPOCA \\ SEPTIEMBRE-DICIEMBRE 2004 \\ 109
}

entre el Ejecutivo y el Legislativo, definidas por la confrontación, la parálisis institucional y los desacuerdos entre los mismos partidos. ${ }^{14}$ Por esta razón y basado en las encuestas que reflejaban una fuerte imagen presidencial, el Gobierno pensó imponer su agenda a un Congreso que tuvo la fuerza para desbaratar momentáneamente la política gubernamental, pero no fue capaz de elaborar una agenda propia. Sin embargo, la viabilidad del Gobierno parece residir paradójicamente en la división , el desprestigio y la falta de iniciativas de los partidos políticos.

En este contexto de impasse institucional, los partidos políticos han seguido por separado sus propios derroteros. Mientras el juego estratégico del MAS se orienta al objetivo de expandir su poder político por la vía de las elecciones municipales de diciembre de 2004, de la asamblea constituyente y de las elecciones generales de 2007, ${ }_{15}^{15}$ ¿Cuáles han sido las estrategias de los partidos que fueron expulsados del Poder Ejecutivo? La impresión predominante es que están involucrados en un regateo particularista de corto plazo, destinado especialmente a mantener las cuotas de poder que les quedan, a minimizar los efectos de una muy probable derrota en las próximas elecciones municipales $y$, supuestamente, a ganar tiempo para resolver sus disputas internas. Pero sus acciones son miopes, no dejan traslucir propósitos de largo plazo y obedecen más a una lógica coyuntural de ventajas inmediatas, relativamente contrarrestada por el apoyo parcial -y muchas veces impuesta por presiones externas- a las iniciativas del Gobierno, que culminó en la aprobación de la ley marco del referéndum la cual incluye una disposición transitoria que legaliza el decreto por el cual Mesa convocó al referéndum sobre la política del gas. ${ }^{16}$

Esta situación no es nada sorprendente porque la crisis de octubre de 2003 desquició completamente a los partidos que eran el eje del sistema político, sumergiéndolos en un grave proceso de división y fragmentación. Como hemos visto, el trípode de partidos dominante (MNR-ADN-MIR) ya se había disuelto en las elecciones de 2002 con la casi desaparición de ADN. Los sobrevivientes, el MNR y el MIR, que no supieron ni pudieron gobernar, cayeron también en un proceso creciente de disgregación. Hundidos en un panorama de extremo desgaste, estos partidos se enfrentan ahora, si es que quieren prolongar su existencia, al enorme desafío de recuperar credibilidad y espacio político. Sin embargo, es dudoso que puedan hacerlo sólo revisando programas políticos y recomponiendo sus cuadros de dirección y sus estructuras internas. Si estarán en condiciones de lograr su recuperación y renovar así el sistema de partidos, es precisamente uno de los interrogantes que

${ }^{14}$ Parlamentarios disidentes de varios partidos formaron una llamada «bancada transversal», a la que pertenecen más de 30 diputados, para aliviar esta situación, pero esto tampoco ha contribuido a superar la situación del Parlamento.

${ }^{15}$ Según Evo Morales «los partidos políticos tradicionales buscan sabotear al Gobierno porque saben que perderán en las elecciones municipales» (La Razón, 11/03/04).

${ }^{16}$ El Congreso descuidó temas importantes y se ocupó de bagatelas como el traslado de la sede congresal o interpelaciones y acusaciones mutuas de tramar golpes de Estado. 
no admiten en este momento ninguna respuesta satisfactoria. El MNR está dividido en por lo menos tres fracciones, y pugna por superar la histórica crisis de liderazgo provocada por la caída de Sánchez de Lozada, aunque no se percibe que tenga la capacidad de construir a corto plazo un nuevo liderazgo con convocatoria política. El MIR ha postergado innumerables veces la realización de elecciones nacionales y está igualmente fraccionado y sin conducción política clara. Una de las razones ha sido que Jaime Paz Zamora se aferra contra viento y marea a un liderazgo cada vez más desgastado y cuestionado. Un grupo dirigido por el empresario Doria Medina ha abandonado el partido con el argumento de que el MIR es ya una organización irremediablemente viciada e irrecuperable, y en enero de 2004 fundó un nuevo partido, el Frente de Unidad Nacional (FUN), organizando a continuación elecciones para sus cargos de dirección. Después de su efímera y oportunista participación en la coalición de Sánchez de Lozada, el NFR está cuestionado por una parte de su bancada parlamentaria que acusa al jefe del partido de caudillismo. El MAS, como partido nuevo que obedece más a una lógica de movimiento social, acaba de sufrir recientemente una grave fractura por la ruptura entre Evo Morales y Filemón Escobar, su principal ideólogo; ruptura que debilita sus perspectivas de construcción partidaria y de fortalecer su presencia en la política nacional. Después de la renuncia de Felipe Quispe a su curul, el MIP está en camino seguro a la extinción.

Por lo tanto, la coyuntura actual está dominada por factores que fortalecerán mucho más las tendencias hacia la descomposición y atomización del sistema de partidos. ${ }^{17}$ Un factor nuevo es, por cierto, la reforma constitucional de febrero de 2004. Sin fuerzas para resistir la corriente antipartido prevaleciente, los propios partidos políticos aprobaron, de manera irreflexiva y con un procedimiento anticonstitucional, un marco institucional chapucero y contradictorio que es muy favorable a la desinstitucionalización del sistema de partidos y la ingobernabilidad.

\section{Conclusiones}

Las conclusiones que se pueden extraer del análisis no son nada alentadoras. En primer término, los partidos políticos, que formaron el eje en torno al cual giró la democracia boliviana, están en un torbellino de descomposición facciosa que refleja una crisis histórica de liderazgo y orientación programática. En consecuencia, el sistema multipartidista polarizado que emergió de las elecciones de 2002 está bajo amenaza de muerte. En segundo

${ }_{17}$ A los 14 partidos políticos reconocidos por la CNE pueden sumarse otras organizaciones que han solicitado su registro: Alianza Renovadora Nacional (Arena), Solidaridad Auténtica y Liberadora (SAL), Nueva Identidad nacional (NIN) y el Partido Socialdemócrata Nacionalista (PSO). El alcalde de El Alto, José Luis Paredes, ex-miembro del MIR, fundará un partido denominado «Plan Progreso» y Roberto de La Cruz, dirigente radical de la COB de El Alto, también pretende organizar un partido llamado «Movimiento 11 de Octubre». El ex-presidente Quiroga, miembro de ADN, piensa desplazar a su partido creando un movimiento «ciudadano». 
La crisis del sistema de partidos políticos

en Bolivia: causas y consecuencias

\author{
CUADERNOS DEL CENDES \\ AÑO 21. N 57 \\ TERCERA ÉPOCA \\ SEPTIEMBRE-DICIEMBRE 2004

\section{1}

término, la crisis política actual ha seguido bajo la tónica del impasse entre el Poder Ejecutivo y el Legislativo, la disgregación de las instituciones y el peligro de ingobernabilidad, dejando un estrecho margen de maniobra al gobierno de Mesa. Los partidos políticos sobreviven atrincherados en el ámbito parlamentario y en reparticiones de la administración estatal. Sobre el horizonte se cierne una crisis de largo plazo del sistema de partidos políticos que hace improbable la emergencia de alternativas duraderas, a corto o mediano plazo, basadas en partidos políticos renovados o nuevos.

En tercer término, una probable recomposición democrática de las condiciones de gobernabilidad sobre la base de los partidos políticos está puesta en cuestión por la masiva estigmatización del principio de la política basada en partidos y, paradójicamente, por el mismo principio consagrado en la reforma constitucional de febrero de 2004, por el cual agrupaciones personalistas, corporativas y temporales de ciudadanos independientes, así como movimientos indígenas, identitarios pueden constituirse como organizaciones de representación política y competir con los partidos políticos. Acecha incluso el peligro de que se frustre la transformación de movimientos sociales como el MAS en partidos políticos de carácter nacional que fuera impulsada por el sistema electoral y la ley de partidos políticos todavía vigentes. Estamos, en consecuencia, en el umbral de un proceso político, alentado por los mismos partido, en el cual movimientos altamente personalizados, con sustentación electoral dispersa y local, harán de la política un campo de lucha por intereses localistas y corporativistas bajo el supuesto de que son superfluos los partidos políticos estructurados de alcance nacional y pueden ser perfectamente reemplazados por esas organizaciones circunstanciales.

La cuestión principal ya no es entonces cómo se podría fortalecer el sistema de partidos o a determinados partidos políticos en particular, sino emprender una tarea más urgente: cómo y bajo qué condiciones los partidos podrían generar estrategias destinadas a su renovación y recuperación en un clima antipartido que ellos mismos han contribuido a crear. Cuando los partidos han dado muestras de ser organismos inadaptables y aquejados por males letales, sólo quedarían como soluciones probables terapias intensivas de emergencia. La analogía biológica y médica plantea un gran dilema: ¿se puede fortalecer y revitalizar a organismos decaídos que aparentemente ya no tienen capacidad de recuperación?

La disyuntiva es, por lo tanto, si es posible hacer propuestas razonables y libres de las expectativas ilusorias que abundan actualmente en el delirante ambiente intelectual del país, cubierto de ideas utópicas y del polvo de dogmas del pasado En todo caso, las propuestas no podrían estar inspiradas directamente en un criterio de fortalecimiento de los partidos políticos, sino en una perspectiva de mayor urgencia que se refiere a cómo afrontar los problemas de supervivencia en una coyuntura de inestabilidad del régimen democrático

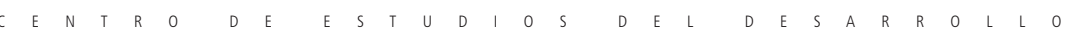


en la cual el factor tiempo se constituye en una variable fundamental. En este sentido, el problema crucial es el de atacar la descomposición interna de las organizaciones partidarias y de la atomización del sistema de partidos. Bajo el supuesto de que el gobierno de Mesa -a pesar de la agenda de octubre- cumpla con su mandato constitucional hasta agosto de 2007, mi propuesta principal es que los partidos políticos deberían aprovechar este precioso tiempo promoviendo dos escenarios de debate y reconstrucción ideológica y organizacional: por un lado, debates democráticos intrapartidarios para luchar contra la desintegración, renovar sus estructuras de dirección y replantear sus ideas y programas; por otro lado, debates interpartidarios sobre las cuestiones fundamentales del país para superar la dispersión política, recuperar poco a poco en el escenario parlamentario la capacidad de hacer política nacional, y recomponer los consensos a través de grandes acuerdos políticos. Una segunda propuesta está encaminada a la necesidad de un cambio fundamental de la concepción de hacer política a fin de reconstruir las relaciones entre el Estado y la sociedad, y de contener el peligroso proceso de degradación de la autoridad y legitimidad de las instituciones estatales. Si quieren sobrevivir, los partidos políticos deben dejar de ser círculos facciosos de manejo prebendal del Estado, y deben desarrollar prácticas de deliberación y concertación con organizaciones sociales, que contribuyan a largo plazo a crear un nuevo modelo de gobernabilidad y vaya más allá del modelo centrado en acuerdos exclusivamente entre partidos políticos. Pero asegurar, en la coyuntura actual, que los partidos puedan cambiar de identidad y adaptarse a los nuevos desafíos es aún muy prematuro.

Argumentado contracorriente, mi tercera propuesta es que los partidos políticos asuman una tarea que tarde o temprano tendrán que acometer: revisar a fondo las fallas y los desperfectos del marco constitucional que ellos acaban de causar mediante la irreflexiva reforma constitucional de febrero de 2004 y con subsiguientes leyes como la de agrupaciones ciudadanas y pueblos indígenas. ¿Será posible mitigar las consecuencias e impactos destructivos del nuevo contexto constitucional, que es, paradójicamente, uno de desestabilización y erosión institucional? Esta cuestión no es ociosa puesto que el sistema democrático ha experimentado trastornos severos que lo erosionan: los partidos y liderazgos políticos han perdido credibilidad y autoridad, las estructuras partidistas están a merced de fuerzas disgregadoras y los políticos tienden a camuflarse como antipolíticos; ha surgido como deseable y hasta factible una democracia «ciudadana» que cree no necesitar de mediaciones políticas y de estructuras representativas, confundiendo así lo social y lo político; ${ }^{18}$ y, por último, bajo la presión de la «agenda de octubre» los partidos políticos han establecido

18 De acuerdo con una encuesta realizada en 2001 por la CNE más del 60 por ciento de la población boliviana estima que la democracia no requiere de los partidos políticos; en el ámbito latinoamericano también se ha constatado recientemente un porcentaje significativamente alto (38 por ciento) de esa opinión (PNUD, 2004).

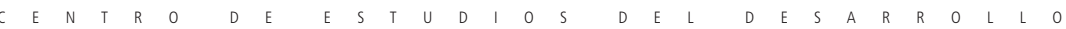


instituciones como la Asamblea Constituyente que admite una «reforma total» de la Constitución política del Estado, consagrando el desmantelamiento institucional y la política antipartido y dando una respuesta errada y desastrosa al problema real de las crisis global de los partidos políticos.

\section{Referencias bibliográficas}

Cameron, Max y Steve Levitzky (2003). «Democracy without Parties? Political Parties and Regime Change in Fujimor's Peru», Latin American Politics and Society, $n^{\circ}$ 3, University of Miami.

Dahl, Robert (1990). After the Revolution? Authority in a Good Society, New Haven, Yale University.

Eder, Klaus (2001). «De los intereses a la identidad y de ésta de vuelta a los intereses. Los límites de la movimientización en la sociedad moderna», en Maíz, Ramón, ed., Construcción de Europa. Democracia y globalización, vol. 1, Santiago de Compostela, Universidad de Santiago de Compostela.

Katz, Richard y Peter Mair (1995). «Changing Models of Party Organization and Party Democracy. The Emergence of the Cartel Party», Party Politics, vol. 1, n 1.

Lijphart, Arend (1999). «Reformas legales y constitucionales del sistema democrático boliviano», Informe de Consultoría para Pronagob, La Paz.

Mainwaring, Scott y Timothy Scully, eds. (1995). Building Democratic Institutions. Party Systems in Latin America, Stanford, Stanford University Press.

MAS (2002). «Territorio, soberanía y vida», Opiniones y análisis. Elecciones generales 2002: propuestas electorales, La Paz, Fundemos.

Mayorga, René Antonio (1991).¿ ¿De la anomia política al orden democrático?, La Paz, Cebem.

Mayorga, René Antonio (1995). Antipolítica y neopopulismo, La Paz, Cebem.

Mayorga, René Antonio (2000). Los diputados uninominales: problemas y redefinición de su rol parlamentario, La Paz, Viceministerio de Participación Popular, Serie Cuadernos de Investigación, $n^{\circ} 5$.

Mayorga, René Antonio (2001a). Desmontaje de la democracia. Crítica de las propuestas de reforma del Diálogo Nacional 2000 y las tendencias antisistémicas, La Paz, Cebem.

Mayorga, René Antonio (2001b). «Electoral Reform in Bolivia: Origins of the Mixed-Member Electoral System», en Shugart, Matthew y Martin Wattenberg, eds., Mixed-Member Electoral Systems. The Best of Both Worlds?, New York, Oxford University Press.

Mayorga, René Antonio (2001c). «Presidencialismo parlamentarizado y gobiernos de coalición en Bolivia», en Lanzaro, Jorge y René Antonio Mayorga, eds., Tipos de presidencialismo y coaliciones políticas en América Latina, Buenos Aires, Clacso.

Mayorga, René Antonio (2001d). «The Mixed-Member Electoral System and Its Consequences in Bolivia», en ibid.

Mayorga, René Antonio (2002). «Democracia y liderazgo político en Bolivia», en Hofmeister, Wilhelm, ed., Democracia y liderazgo político en América Latina, Río de Janeiro, Fundación Adenauer.

Movimiento Indígena Pachekuti (MIP) (2002). «Poder, tierrra y territorio», Opiniones y análisis, Elecciones generales 2002: propuestas electorales, La Paz, Fundemos. 
CUADERNOS DEL CENDES

René Antonio Mayorga

AÑ̃ 21. N 57

$114 \begin{aligned} & \text { Tercera ÉPOCA } \\ & \text { SePtiembre-DiCIEMBre } 2004\end{aligned}$

Programa de las Naciones Unidas para el Desarrollo (PNUD) (2004), La democracia en América Latina. Hacia una democracia de ciudadanos, Nueva York, PNUD.

Samuels, David y Richard Snyder (2001). «The Value Vote: Malapportionment in Comparative Perspective», British Journal of Political Science, $n^{\circ} 31$

Sartori, Giovanni (1987). Partidos y sistemas de partidos, Madrid, Alianza Editorial.

Sartori, Giovanni (1988). Teoría de la democracia. 1. El debate contemporáneo, Madrid, Alianza Editorial.

Zovatto, Daniel (2000). «La vida en el interior de los partidos políticos, El tema de las elecciones internas», manuscrito. 